\title{
BONDING EFFECTIVENESS OF BIOACTIVE SELF-ADHESIVE RESTORATIVE MATERIAL TO ENAMEL AND DENTIN USING DIFFERENT BONDING PROTOCOLS
}

\author{
Mayada S. Sultan*, Maha E. Elkorashy ${ }^{* *}$ and A. Fawzy ${ }^{* * *}$
}

\begin{abstract}
Objective: To investigate microshear bond strength of bioactive restorative material to enamel and dentin bonded using universal adhesive in etch and rinse and self-etch mode stored for $24 \mathrm{~h}$ and $6 \mathrm{~m}$.

Methods: Sound bovine incisors were used in this study. ACITVA Bioactive Restorative (Pulpdent Corp., Watertown, MA, USA) and Single Bond Universal adhesive (3M ESPE, St.Paul, MN, USA) were used. Teeth were grouped into 6 groups according to tooth substrate (enamel and dentin) and bonding protocol (No bonding agent, bonding in etch and rinse mode and bonding in self-etch mode). Specimens were stored for either $24 \mathrm{~h}$ or $6 \mathrm{~m}$. Microshear bond strength $(\mu \mathrm{SBS})$ was tested using universal testing machine and micromorphological observation of the interface was investigated using ESEM. Data were tabulated and statistically analyzed using Two-way ANOVA followed by Bonferroni's post-hoc test.
\end{abstract}

Results: Enamel bonded in etch and rinse mode recorded the highest $\mu$ SBS values at both storage periods. Dentin at $24 \mathrm{~h}$ showed no significant difference between etch and rinse and selfetch modes while after $6 \mathrm{~m}$, etch and rinse protocol showed significant drop. Control group recorded the lowest $\mu$ SBS at all experimental groups.

Conclusion: Use of bonding agents is recommended with ACITVA to both enamel and dentin. Universal adhesives are preferred in etch and rinse mode with enamel and self-etch mode with dentin. ACITVA is able to preserve bond strength upon storage except for dentin bonded in etch and rinse mode.

KEY WORDS: Bioactive material, Microshear bond strength, Bonding protocols, Etch and rinse, Self-etch.

* Lecturer, Operative Dentistry Department, Faculty of Dentistry, Fayoum University.

** Associate Professor, Operative Dentistry Department, Faculty of Dentistry, Fayoum University.

*** Assistant Professor, Operative Dentistry Department, Faculty of Dentistry, Suez Canal University. 


\section{INTRODUCTION}

The tooth / restoration interface is the most critical area in the restorative system. Dealing with the problems associated with the tooth restoration interface could improve the overall performance of the restoration. ${ }^{(1)}$ Moreover, the harsh oral environmental factors such as temperature changes, fluctuating $\mathrm{pH}$, bacterial enzymes, and aqueous nature limit the durability of dental restorations. ${ }^{(2)}$ Proper bonding should be achieved along the bonded interface represented in enamel and dentin tissues. Failure of interfacial bond will develop marginal gaps that might continue till restoration loss. ${ }^{(3)}$

The presence of restorative materials with adhesive potential as glass ionomer cements (GICs) could provide better performance as they are able to chemically bond to both enamel and dentin. ${ }^{(4)}$ Resin modified glass ionomer cements (RMGICs) were developed to improve the physical and mechanical properties of conventional GICs. ${ }^{(1)}$ Continuous development of material science has resulted in the introduction of bioactive restorative materials. ${ }^{(5)}$

ACTIVA BioActive Restorative (Pulpdent Corp., Watertown, MA, USA) is a novel bioactive, flowable, resin-based composite material comparable to RMGICs. It is composed of fluoro-aluminosilicate particles and polyacid components of the conventional glass ionomer thus; it sets by an acid-base reaction. Moreover, it contains a bioactive ionic resin matrix which allows light and chemical polymerization hence, it undergoes three hardening mechanisms. ACTIVA BioActive Restorative resembles the physical and chemical properties of the natural teeth as reported by the manufacturer as it is composed of bioactive ionic resin matrix, shock absorbing resin components and reactive GI fillers. Manufacturer also reported that this material has a self-adhesive property that eliminates the need for bonding agents, in addition to its capacity to release ions as calcium, phosphate and fluoride upon storage in saliva. ${ }^{(6)}$
Adhesive dentistry is constantly evolving in an attempt to improve bond durability and marginal adaptation of restorations. Innovations in bonding agents and bonding strategies to provide strong and stable bond with enamel and dentin are greatly challenging ${ }^{(3)}$ due to their vastly different structures in terms of composition and natural variability. ${ }^{(7)}$ Universal adhesive (multi-mode) systems become very popular in daily dental practices. They are called universal systems as they could be used in different modes as etch and rinse and self-etch modes, with different substrates as enamel and dentin to be bonded to both direct and indirect restorations. ${ }^{(7-9)}$ Considering their composition, universal adhesives can be classified as simplified systems because all ingredients, including acidic functional monomers and solvents, are incorporated into one bottle maintaining the "all-in-one" philosophy. ${ }^{\left({ }^{8}\right)}$ They are similar to one-step self-etch adhesive systems, so they still have presented some issues regarding their bonding performance, degradation, and longevity. ${ }^{(9)}$

Chemical adhesion to tooth tissue occurs as a result of an ion exchange process at the tooth/ restoration interface. This is attributed to chelation of the calcium ions in the surface of the hydroxyapatite layer ${ }^{(2)}$ which might be more evident upon storage in biological fluid as saliva. Hence, the current study was conducted to investigate the bond strength of ACITVA bioactive restorative to both enamel and dentin using universal adhesive in etch and rinse and self-etch mode upon 6 months' storage.

\section{MATERIALS AND METHODS}

\section{Materials Used in the Study}

The materials used this study, manufacturer, composition and lot number are shown in table 1 .

\section{Specimens' Preparation and Grouping}

A total of 72 sound bovine incisors were used in the current study. The teeth were thoroughly washed under running water, scaling was done to remove 
plaque and calculus. Teeth were stored in distilled water at $4^{\circ} \mathrm{C}$ for not more than one month. The teeth were divided into 6 groups (12 bovine teeth per group) according to the bonding substrate (enamel, dentin) and the bonding protocol (No bonding agent, etch and rinse, self-etch) as shown in table 2 . Bovine teeth for each group were subdivided into two subgroups according to the storage period either $24 \mathrm{~h}$ or $6 \mathrm{~m}(\mathrm{n}=6)$. For each subgroup, 5 bovine teeth were used for microshear bond strength testing and 1 tooth for ESEM observation. Each bovine tooth was bonded with 2 ACTIVA specimens.

Roots of the incisors were horizontally sectioned below the cemento-enamel-junction by $2 \mathrm{~mm}$. Crowns were mounted in self-cured acrylic resin using metal molds $(2 \mathrm{~cm} \times 3 \mathrm{~cm})$ with the labial surface facing upward. In enamel groups, enamel was wet ground using 80 grit sandpaper discs to achieve flat enamel surfaces. Regarding dentin groups, enamel was totally removed until reaching flat dentin surfaces. A uniform smear layer was then achieved using wet 600 grit sandpaper discs for both enamel and dentin specimens.

\section{Bonding Procedures}

In groups bonded with universal adhesive (group $2,3,5,6)$, bonding agent was applied according to the bonding protocol assigned either in etch and rinse mode or self-etch mode as stated in table 2. Etching was done using 37\% phosphoric acid etchant gel (UltraEtch ${ }^{\circledR}$, ULTRADENT, Inc, USA). Enamel was etched for $30 \mathrm{sec}$ and dentin for $15 \mathrm{sec},{ }^{(10)}$ rinsed under running water and gently dried. Two coats of Single Bond Universal adhesive (3M ESPE,

TABLE (1) Materials used in the study, manufacturer, composition and lot number

\begin{tabular}{|c|c|c|c|}
\hline Material & Manufacturer & Composition & Lot no. \\
\hline $\begin{array}{l}\text { ACTIVA Bioactive } \\
\text { Restorative Glass }\end{array}$ & $\begin{array}{c}\text { (Pulpdent Corp., } \\
\text { Watertown, MA, USA) }\end{array}$ & $\begin{array}{c}\text { Blend of diurethane and other methacrylates with modified } \\
\text { polyacrylic acid }(44.6 \%) \text {, amorphous silica }(6.7 \%) \text {, and } \\
\text { sodium fluoride }(0.75 \%) \text {. no Bisphenol A, no BisGMA, no } \\
\text { BPA derivatives. } \\
56 \% \text { by weight reactive glass particles shock absorbing } \\
\text { ionic resin component containing acidic monomer with } \\
\text { antimicrobial properties. }\end{array}$ & 180425 \\
\hline $\begin{array}{c}\text { Single Bond Universal } \\
\text { adhesive }\end{array}$ & $\begin{array}{c}\text { (3M ESPE, St.Paul, MN, } \\
\text { USA) }\end{array}$ & $\begin{array}{l}10 \text { MDP phosphate monomer, dimethacrylate resins, } \\
\text { HEMA, polyalkenoic acid copolymer, filler, ethanol, water, } \\
\text { initiators, silane. }\end{array}$ & 606115 \\
\hline
\end{tabular}

TABLE (2) Specimens grouping, bonding substrate \& protocol and bonding procedure

\begin{tabular}{|c|l|l|}
\hline Group & \multicolumn{1}{|c|}{ Bonding substrate \& Protocol } & \multicolumn{1}{c|}{ Bonding procedure } \\
\hline Group 1 & Enamel (Control) & No bonding agent \\
\hline Group 2 & Enamel in Etch \& rinse mode (E+ER) & 30 sec etching with 37\% phosphoric acid + Universal adhesive \\
\hline Group 3 & Enamel in Self-etch mode (E+SE) & Universal adhesive \\
\hline Group 4 & Dentin (Control) & No bonding agent \\
\hline Group 5 & Dentin in Etch \& rinse mode (D+ER) & 15 sec etching with 37\% phosphoric acid + Universal adhesive \\
\hline Group 6 & Dentin in Self-etch mode (D+SE) & Universal adhesive. \\
\hline
\end{tabular}


St.Paul, MN, USA) were applied using disposable microbrushs. Rubber microtubes of $0.8 \mathrm{~mm}$ diameter and $1 \mathrm{~mm}$ height (Harvard tubing, USA) were placed on the treated enamel and dentin surfaces of the specimens before light curing of the adhesive resin. The adhesive resin was then light cured using LED light curing unit (Elipar S10 free light 3M ESPE) with light intensity $1200 \mathrm{~mW} / \mathrm{cm}^{2}$ for $10 \mathrm{sec}$ according to the manufacturer's instructions.

Rubber microtubes were filled with ACITVA restorative material and left for $20 \mathrm{sec}$ before curing following the manufacturer's instructions. The rubber microtubes were covered with celluloid strips (Stripmat, POLYDENTIA, CH-6805 Mezzovico, Switzerland) and cured for $20 \mathrm{sec}$ with a total number of 20 specimens for each group (10 specimens were stored for $24 \mathrm{~h}$ and the other 10 specimens for $6 \mathrm{~m}$ ). After curing, the rubber microtubes were sectioned longitudinally using sharp scalpel and removed. Samples which were debonded during removal of rubber microtubes, were excluded. The specimens were then stored in artificial saliva for $24 \mathrm{~h}$ before testing. Regarding group 1 and group 4, ACTIVA Bioactive Restorative was applied directly to tooth substrate using the same procedures as mentioned before.

\section{Microshear Bond Strength Testing ( $\mu$ SBS)}

Half of the specimens for each group were subjected to microshear bond strength test after $24 \mathrm{~h}$ using a universal testing machine (Lloyd LR 5K, Lloyd Instruments Ltd, Hampshire, UK) with a cross head speed of $0.5 \mathrm{~mm} / \mathrm{min}$. A thin metal wire (0.2 $\mathrm{mm}$ diameter) was looped around each restoration cylinder and gently held flushing with the interface. The metal wire was secured in the upper compartment of the universal testing machine. Each restorative material cylinder was loaded to failure, and the force required for debonding was divided by the bonded area of the specimens to express the bond strength values in MPa.

\section{Storage of Specimens in Artificial Saliva}

The other half of the specimens for each group were stored in artificial saliva for $6 \mathrm{~m}$ at $37^{\circ} \mathrm{C}$ in incubator (Titanox, TITANOX art. A3-213-4001 Co. Torrede Picenardi (CR), Itlay). Artificial saliva was prepared according to guidelines assigned by Rodrigues et al, 2007. ${ }^{(11)}$ The composition of the artificial saliva is as follows: $50 \mathrm{mmol} / \mathrm{L}$ potassium chloride, $1.5 \mathrm{mmol} / \mathrm{L}$ calcium, $0.9 \mathrm{mmol} / \mathrm{L}$ phosphate, 20 $\mathrm{mmol} / \mathrm{L}$ Trihydroxyl methyl-amino methane (Tris) diluted in one litre of distilled water.

\section{Environmental Scanning Electronic Microscopic Observation}

For each group, representative specimens $(3 \mathrm{~mm}$ width $\times 2 \mathrm{~mm}$ height) were prepared with the same protocol mentioned before and examined under environmental scanning electron microscope (ESEM) (Model: (FEI - inspect S) fitted with EDAX unit for $\mathrm{X}$-ray microanalysis). The specimens were sectioned into two halves to expose the interface using low speed diamond disc under copious amount of water. The sectioned surfaces were flattened and smoothed using ascending grits 320, 600 and 1200 of sandpaper discs. Each sectioned surface was etched for 20 sec using 37\% phosphoric acid gel and rinsed for another $20 \mathrm{sec}$. The specimens were immersed in $5.25 \% \mathrm{NaOCl}$ for $10 \mathrm{~min}$ to deproteinize organic material, washed under running water for $5 \mathrm{~min}$ and then dried. ${ }^{(12)}$ ESEM model is characterized by low vacuum mode which allows investigation of samples without the need for coating. Tested specimens were mounted on metal stubs, images from the selected sample were obtained at $1200 \mathrm{X}$ magnification.

\section{Statistical Analysis:}

Numerical data were explored for normality by checking the distribution of data and using tests of normality (Kolmogorov-Smirnov and Shapiro-Wilk tests). Microshear bond strength data showed parametric distribution. Data were presented as mean and standard deviation (SD) values. Three-way Analysis of Variance (ANOVA) was used to study 
the effect of bonding protocol, storage period, tooth substrate and their interaction on mean microshear bond strength. Bonferroni's post-hoc test was used for pair-wise comparisons when ANOVA test reveals significance. The significance level was set at $\mathrm{P} \leq 0.05$. Statistical analysis was performed with IBM SPSS Statistics for Windows, Version 23.0. Armonk, NY:IBM Corp.

\section{RESULTS}

\section{Results of Microshear Bond Strength}

Regarding the effect of different bonding protocols as shown in table 3, enamel recorded the highest shear bond strength values when bonded in etch and rinse mode followed by self-etch mode, while control group showed the lowest bond strength value with a statistically significant difference. This finding was evident at both storage periods.
Shear bond strength to dentin at $24 \mathrm{~h}$ demonstrated no significant difference between etch and rinse mode and self-etch mode with significantly higher values than the control group. At $6 \mathrm{~m}$ storage, self-etch mode showed the highest mean values in comparison to other groups with significant drop associated with etch and rinse mode. Control group showed the lowest bond strength results.

Regarding the effect of storage period, all experimental groups revealed no significant difference between $24 \mathrm{~h}$ and $6 \mathrm{~m}$ except for dentin substrate bonded using etch and rinse mode which showed significant drop in bond strength after $6 \mathrm{~m}$ storage (table 4).

Statistical analysis for the effect of tooth substrate reported that enamel showed significantly higher mean shear bond strength than dentin for different bonding protocols and at both $24 \mathrm{~h}$ and $6 \mathrm{~m}$ as shown in table 5 .

TABLE (3) Mean and standard deviation (SD) values for the effect of bonding protocol on microshear bond strength

\begin{tabular}{|c|c|c|c|c|c|c|c|c|c|}
\hline & \multirow{2}{*}{$\begin{array}{c}\text { Tooth } \\
\text { substrate }\end{array}$} & \multicolumn{2}{|c|}{ Control } & \multicolumn{2}{|c|}{ Etch and Rinse } & \multicolumn{2}{|c|}{ Self-etch } & \multirow{2}{*}{$P$-value } & \multirow{2}{*}{$\begin{array}{c}\text { Effect size (Partial } \\
\text { eta squared) }\end{array}$} \\
\hline & & Mean & SD & Mean & SD & Mean & $\mathrm{SD}$ & & \\
\hline \multirow{2}{*}{$\begin{array}{c}24 \\
\text { hours }\end{array}$} & Enamel & $14.2^{\mathrm{C}}$ & 1.6 & $34.1^{\mathrm{A}}$ & 1.6 & $24.3^{\mathrm{B}}$ & 1.2 & $<0.001^{*}$ & 0.884 \\
\hline & Dentin & $7.7^{\mathrm{B}}$ & 1.5 & $17.2^{\mathrm{A}}$ & 1.9 & $16.3^{\mathrm{A}}$ & 1.9 & $<0.001^{*}$ & 0.683 \\
\hline \multirow{2}{*}{$\begin{array}{c}6 \\
\text { months }\end{array}$} & Enamel & $13.6^{\mathrm{C}}$ & 1.9 & $32.6^{\mathrm{A}}$ & 1.9 & $23.3^{\mathrm{B}}$ & 1.7 & $<0.001 *$ & 0.875 \\
\hline & Dentin & $8.2^{\mathrm{C}}$ & 1.5 & $10.1^{\text {в }}$ & 0.9 & $16.2^{\mathrm{A}}$ & 1.4 & $<0.001 *$ & 0.575 \\
\hline
\end{tabular}

*: Significant at $P \leq 0.05$, Different superscripts in same row indicates significant difference

TABLE (4) Mean and standard deviation (SD) values for the effect of storage period on microshear bond strength

\begin{tabular}{|c|l|c|c|c|c|c|c|}
\hline \multirow{2}{*}{$\begin{array}{c}\text { Tooth } \\
\text { substrate }\end{array}$} & \multirow{2}{*}{ Bonding protocol } & \multicolumn{2}{|c|}{24 hours } & \multicolumn{2}{|c|}{6 months } & \multirow{2}{*}{ P-value } & $\begin{array}{c}\text { Effect size (Partial } \\
\text { eta squared) }\end{array}$ \\
\cline { 3 - 7 } & & Mean & SD & Mean & SD & & 0.007 \\
\hline \multirow{3}{*}{ Enamel } & Control & $14.2^{\mathrm{A}}$ & 1.6 & $13.6^{\mathrm{A}}$ & 1.9 & 0.515 & 0.041 \\
\cline { 2 - 7 } & Etch and Rinse & $34.1^{\mathrm{A}}$ & 1.6 & $32.6^{\mathrm{A}}$ & 1.9 & 0.115 & 0.006 \\
\cline { 2 - 7 } & Self-etch & $24.3^{\mathrm{A}}$ & 1.2 & $23.3^{\mathrm{A}}$ & 1.7 & 0.262 & 0.006 \\
\hline \multirow{3}{*}{ Dentin } & Control & $7.7^{\mathrm{A}}$ & 1.5 & $8.2^{\mathrm{A}}$ & 1.5 & 0.544 & 0.493 \\
\cline { 2 - 7 } & Etch and Rinse & $17.2^{\mathrm{A}}$ & 1.9 & $10.1^{\mathrm{B}}$ & 0.9 & $<0.001^{*}$ & 0.0001 \\
\cline { 2 - 7 } & Self-etch & $16.3^{\mathrm{A}}$ & 1.9 & $16.2^{\mathrm{A}}$ & 1.4 & 0.902 & \\
\hline
\end{tabular}

* Significant at $P \leq 0.05$, Different superscripts in same row indicates significant difference 
TABLE (5) Mean and standard deviation (SD) values for the effect of tooth substrate on microshear bond strength

\begin{tabular}{|c|l|c|c|c|c|c|c|}
\hline \multirow{2}{*}{$\begin{array}{c}\text { Storage } \\
\text { period }\end{array}$} & \multicolumn{1}{|c|}{$\begin{array}{c}\text { Bonding } \\
\text { protocol }\end{array}$} & \multicolumn{2}{|c|}{ Enamel } & \multicolumn{2}{c|}{ Dentin } & \multirow{2}{*}{ P-value } & \multirow{2}{*}{$\begin{array}{c}\text { Effect size (Partial } \\
\text { eta squared) }\end{array}$} \\
\cline { 3 - 7 } & Mean & SD & Mean & SD & & 0.455 \\
\hline \multirow{2}{*}{$\begin{array}{c}24 \\
\text { hours }\end{array}$} & Control & $14.2^{\mathrm{A}}$ & 1.6 & $7.7^{\mathrm{B}}$ & 1.5 & $<0.001^{*}$ & 0.360 \\
\cline { 2 - 8 } & Etch and Rinse & $34.1^{\mathrm{A}}$ & 1.6 & $17.2^{\mathrm{B}}$ & 1.9 & $<0.001^{*}$ & 0.847 \\
\cline { 2 - 8 } & Self-etch & $24.3^{\mathrm{A}}$ & 1.2 & $16.3^{\mathrm{B}}$ & 1.9 & $<0.001^{*}$ & 0.907 \\
\hline \multirow{3}{*}{6 months } & Control & $13.6^{\mathrm{A}}$ & 1.9 & $8.2^{\mathrm{B}}$ & 1.5 & $<0.001^{*}$ & 0.552 \\
\cline { 2 - 8 } & Etch and Rinse & $32.6^{\mathrm{A}}$ & 1.9 & $10.1^{\mathrm{B}}$ & 0.9 & $<0.001^{*}$ & 0.490 \\
\cline { 2 - 7 } & Self-etch & $23.3^{\mathrm{A}}$ & 1.7 & $16.2^{\mathrm{B}}$ & 1.4 & $<0.001^{*}$ & \\
\hline
\end{tabular}

*: Significant at $P \leq 0.05$, Different superscripts in same row indicates significant difference

\section{Results of Environmental Scanning Electronic Microscopic observation}

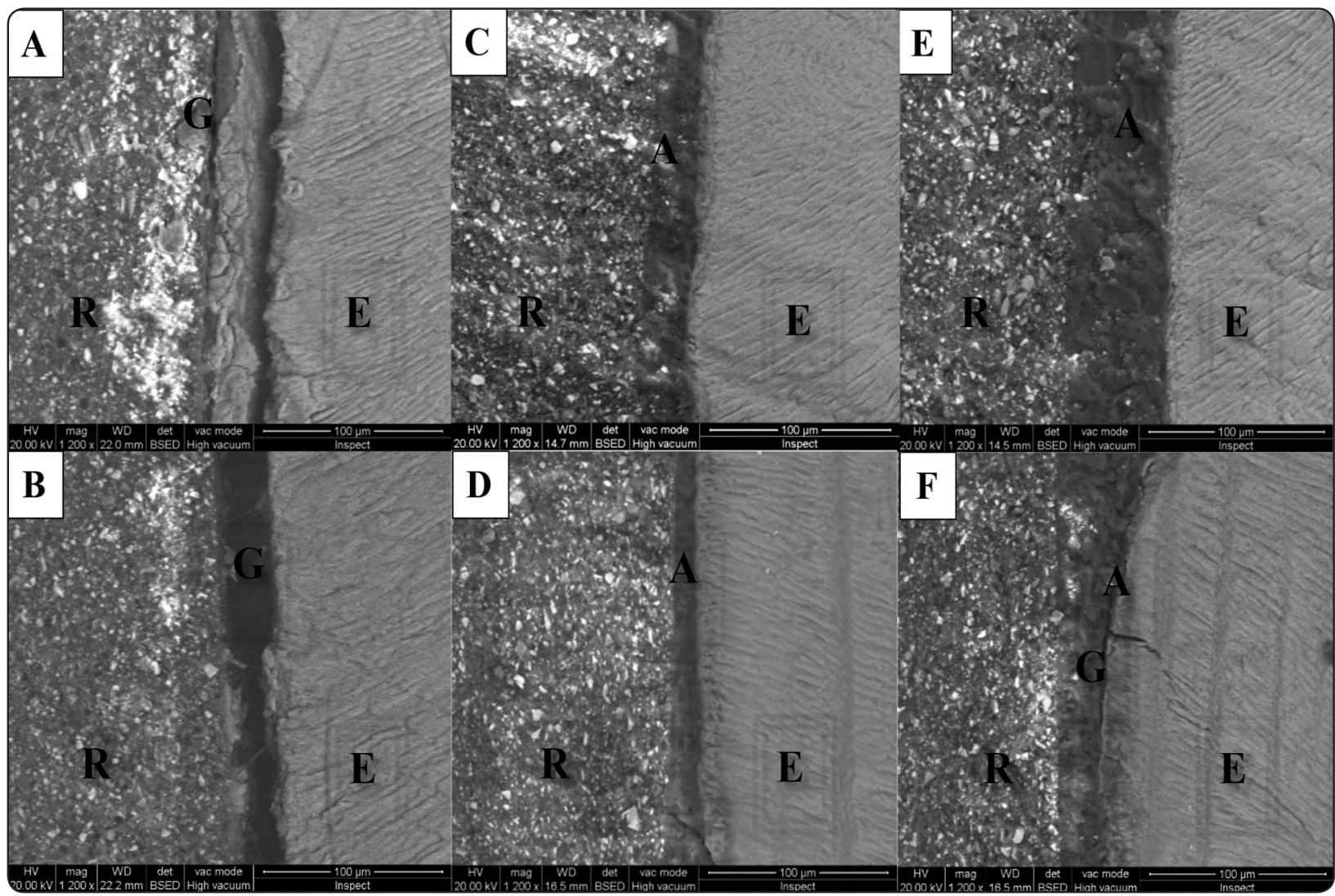

Fig. 1 (A-F): Representative ESEM images of enamel specimens for all tested groups at 1200 X magnification. Fig.1A: Enamel bonded directly to ACTIVA at $24 \mathrm{~h}$ storage showing small gap distance between enamel and ACTIVA with fracture in enamel along the interface. Fig.1B: Enamel bonded directly to ACTIVA after $6 \mathrm{~m}$ storage revealing wide interfacial gap with evidence of formation of interlinking mesh of minerals within the interface. Fig.1C: Enamel bonded to ACTIVA in etch and rinse mode at $24 \mathrm{~h}$ showing intact adhesive interface. Fig.1D: Enamel bonded to ACTIVA in etch and rinse mode at $6 \mathrm{~m}$ reporting no changes at the interface with uniform intact adhesive joint. Fig.1E: Enamel bonded to ACTIVA in selfetch mode at $24 \mathrm{~h}$ revealing thick adhesive junction with no gap formation. Fig.1F: Enamel bonded to ACTIVA in self-etch mode at $6 \mathrm{~m}$ demonstrating localized gap area with evidence of fracture at enamel tissue. (R; restoration, E; enamel, G; gap, A; adhesive) 


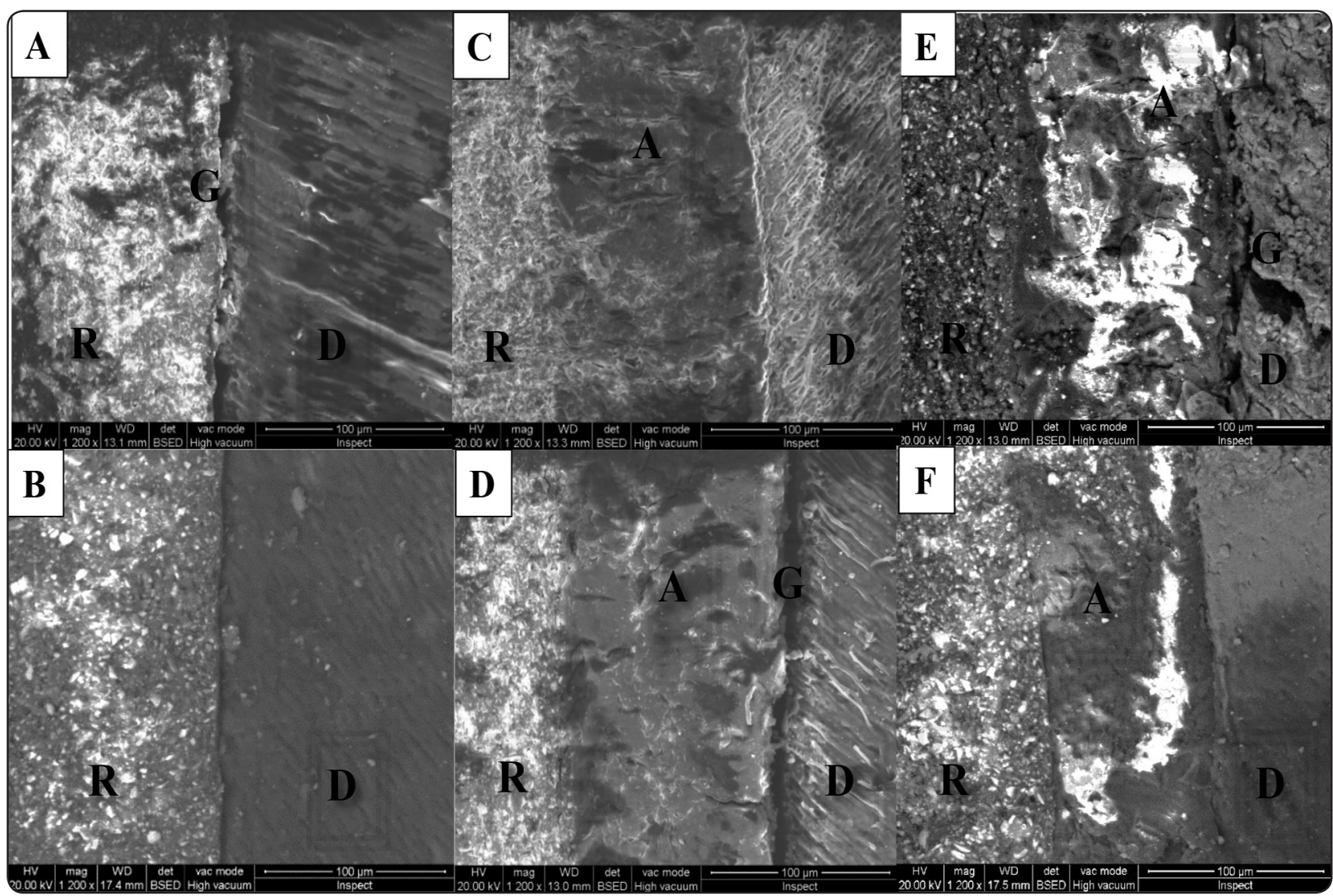

Fig. 2 (A-F): Representative ESEM images of dentin specimens for all tested groups at 1200 X magnification. Fig.2A: Dentin bonded directly to ACTIVA at $24 \mathrm{~h}$ demonstrating gap formation that differs in width at different areas along the interface. Fig.2B: Dentin bonded directly to ACTIVA at $6 \mathrm{~m}$ showing a gap-free uniform adhesive junction. Fig.2C: Dentin bonded to ACTIVA in etch and rinse mode at $24 \mathrm{~h}$ revealing intact and properly sealed adhesive joint. Fig.2D: Dentin bonded to ACTIVA in etch and rinse mode at $6 \mathrm{~m}$ showing gap formation along the adhesive interface. Fig.2E: Dentin bonded to ACTIVA in self-etch mode at $24 \mathrm{~h}$ reporting a small gap at specific area with evidence of fracture in dentin substrate. Fig.2F: Dentin bonded to ACTIVA in self-etch mode at $6 \mathrm{~m}$ showing proper seal along the adhesive interface. (R; restoration, D; dentin G; gap, A; adhesive)

\section{DISCUSSION}

In the current study,ACITVAbioactive restorative was bonded to enamel and dentin either directly without bonding agent following manufacturer's instructions or using universal adhesive applied in etch and rinse or self-etch modes and microshear bond strength was tested after $24 \mathrm{~h}$ and $6 \mathrm{~m}$ storage periods.

Results showed that enamel etched for $30 \mathrm{sec}$ before application of universal adhesive resulted in the highest bond strength results followed by those bonded in self-etch mode. This finding was observed at both storage periods; $24 \mathrm{~h}$ and $6 \mathrm{~m}$.
This was in accordance with Da rosa et al, 2015 ${ }^{(8)}$, Cuevas-Suarez et al, $2019^{(13)}$ and Pouyanfar et al, $2018^{(14)}$. This might be explained by the higher surface area of enamel achieved with phosphoric acid etching in comparison to that achieved using a mild universal adhesive as Single Bond Universal adhesive (pH 2.7) without prior etching. ${ }^{(8,13)}$ Etching results in formation of surface microporosities with subsequent infiltration of adhesive resin forming resin tags with a length of $15-20 \mu .^{(14)}$

However, direct application of ACITVA to enamel without using bonding agent showed the lowest $\mu$ SBS results. Modified polyacrylic acid, 
which is one of the components of ACTIVA, is responsible for etching of tooth structure during material application. ${ }^{(15)}$ It is considered a week acid to perform changes in smear layer to reach micromechanical bonding and this might explain this result.

All enamel groups after 6 months storage, whether bonded using adhesive system in etch and rinse mode, self-etch mode or directly bonded to ACITVA, showed stable bond strength which might be related to the bioactivity of ACITVA. Sauro et al, $2019^{(9)}$ reported that the use of modern ionreleasing restorative materials such as ACTIVA may preserve the bonding performance of those universal adhesives that are more prone to degradation after aging. ESEM images of enamel specimens bonded directly to ACTIVA demonstrated the formation of interlinking mesh of minerals at the interfacial gaps between enamel and ACITVA after $6 \mathrm{~m}$ storage (fig. 1B) as a possible result of the bioactive reaction of ACITVA in the artificial saliva. In etch and rinse and self-etch mode groups, no gaps were observed at the ESEM images at both storage periods (fig. 1C, $1 \mathrm{D}, 1 \mathrm{E} \& 1 \mathrm{~F})$.

Regarding dentin groups, no significant difference was recorded between dentin groups bonded in etch and rinse mode and self-etch mode at $24 \mathrm{~h}$. Etch-and-rinse adhesive systems depend in their adhesive strategy on complete removal of smear layer, teeth demineralization and exposure of collagen mesh with a depth that may range from $5 \mu \mathrm{m}$ to $10 \mu \mathrm{m}$. $^{(16,17)}$ Hence, proper hybrid layer could be achieved through the impregnation of resin monomers into the exposed collagen mesh resulting in high bond strength values which depend mainly on micro-mechanical bonding. ${ }^{(18)}$

However, bonding to dentin in self-etch mode using mild or ultra-mild self-etch adhesive systems depends on two-fold adhesion mechanism (i.e. micro-mechanical and chemical adhesion) as it partially demineralizes dentin producing micro- mechanical hybridization leaving hydroxyapatite crystals. ${ }^{(19,20)}$ These hydroxyapatite crystals present around partially exposed collagen fibers are responsible for the chemical bonding ability with specific functional monomers. ${ }^{(7,19)}$

One of the constituents of Single Bond Universal adhesive is the 10- methacryloyloxydecyl dihyf drogen phosphate (10 MDP) that is able to form an ionic interaction with hydroxyapatite as reported by Yoshihara et al, $2010^{(21)}$. X-ray diffraction (XRD) has demonstrated the presence of an ionic interaction between hydroxyapatite and 10-MDP at the tooth-adhesive interface of both enamel and dentin. (21) The chemical bonding between calcium salts and 10-MDP could contribute to its low dissolution rate and enhance its stability upon storage. ${ }^{(13,19)}$

It seems that bonding mechanisms of both etch and rinse mode and self-etch mode to dentin resulted in a comparable $24 \mathrm{~h}$ bond strength results. This was in agreement with Isolan et al, $2014^{(10)}$ and Hanabusa et al, $2012^{(22)}$ as both researches observed similar dentin bond strength values using a universal adhesive in the etch and rinse and selfetch mode.

After $6 \mathrm{~m}$ of storage in artificial saliva, dentin specimens etched with phosphoric acid showed massive drop in microshear bond strength results. This was confirmed by the ESEM finding as shown in fig.2D. This finding was in accordance with $D e$ Cardoso et al, $2019^{(23)}$ who demonstrated a drop in bond strength results to etched dentin after storage. Armstong et al, $2017^{(24)}$, stated that $6 \mathrm{~m}$ storage for testing dentin bond strength is considered a medium to long term aging period. Da Rosa et al, $2015^{(8)}$ demonstrated degradation of hybrid layer formed by etch and rinse adhesives evidenced by water uptake and loss of cross linking of collagen fibrils. Matos et al, $2017^{(7)}$, suggested that acid etching to dentin removes the inorganic component of dentin leaving exposed collagen fibrils which should be protected by an intimate and complete impregnation of resin 
monomers from the bonding agent. Moreover, phosphoric acid might result in formation of deep microporosities greater than the resin infiltrating potential leaving unprotected collagen fibers which are highly vulnerable to both hydrolytic and enzymatic degradation. ${ }^{(23,25)}$

In addition, activation of matrix metalloproteinase enzymes (MMPs) due to dentin etching using such aggressive phosphoric acid might be another explanation for the diminished durability of microshear bond strength results. ${ }^{(23)}$

Bonding to dentin using self-etch mode demonstrated stable bond strength results at $6 \mathrm{~m}$ storage which was also demonstrated in fig. $2 \mathrm{~F}$. As mentioned before, mild adhesives with a $\mathrm{pH}$ greater than 1.5 as Single Bond Universal results in partial demineralization of dental tissues and chemically interacts with the remaining hydroxyapatite. ${ }^{(20)}$ Accordingly, mild adhesives only expose dentin collagen very superficially, creating a nanoscaled hybrid layer also referred to as nano-interdiffusion zone. ${ }^{(19)}$ Formation of a thin hybrid layer is less prone to hydrolysis. Partial demineralization of dentin and consequent bonding to remaining hydroxyapatite also counts for a more stable and durable bonding interface. ${ }^{(20,26)}$

ACITVA Bioactive Restorative has the ability of fluoride release. ${ }^{(15,27)}$ Release of fluoride might cause inhibition of active metalloproteinases (28) , thus reducing the enzymatic degradation at the bonding interface. Also, possible diffusion of calcium and phosphate ions through permeable hybrid layers might precipitate and crystallize in complex calcium-phosphates and inhibit MMPs through the formation of a Ca-PO/MMP complex. ${ }^{(29)}$

Dentin specimens bonded directly with ACITVA showed significantly low bond strength results at 24 $\mathrm{h}$ but durable on storage. As previously mentioned, ${ }^{(9)}$ modern ion-releasing restorative materials might have the ability of preserving bonding performance of universal adhesives vulnerable to degradation over time.
Bond strength of ACITVA Bioactive Restorative to enamel was significantly higher than that to dentin in all experimental groups before and after storage in artificial saliva which is mostly owed to the histological difference between enamel and dentin tissues.

\section{CONCLUSIONS}

Under the limitations of the current study we could conclude that use of bonding agent is greatly recommended with ACITVA Bioactive Restorative to both enamel and dentin. Universal adhesives are preferred in etch and rinse mode with enamel and self-etch mode with dentin. ACITVA Bioactive Restorative is able to preserve bond strength upon storage except for dentin bonded in etch and rinse mode.

\section{REFRENCES}

1. Ahmed AA, Hassan MM and Abdalla AI: Microshear bond strength of universal adhesives to dentin used in total-etch and self-etch modes. Tanta Dental Journal 2018;15:91-98.

2. Gjorgievska E, Nicholson JW, Iljovska S and Slipper IJ: Marginal adaptation and performance of bioactive dental restorative materials in deciduous and young permanent teeth. Journal of Applied Oral Science 2008;16(1):1-6.

3. Bortolotto T, Bahillo J, Richoz O, Hafezi F and Krejci I: Failure analysis of adhesive restorations with SEM and OCT: from marginal gaps to restoration loss. Clinical Oral Investigations 2015;19:1881-1890.

4. Omidi BR, Naeini FF, Dehghan H, Tamiz P, Savadroodbari MM and Jabbarian R: Microleakage of an enhanced resinmodified glass ionomer restorative material in primary molars. Journal of Dentistry (Tehran) 2018;15(4): 205-213.

5. Alrahlah A: Diametral tensile strength, flexural strength, and surface microhardness of bioactive bulk fill restorative. Journal of Contemporary Dental Practice 2018;19(1):13-19.

6. PULPDENT®. Dental Innovation Since 1947. Products ACTIVA $^{\mathrm{TM}}$ BioACTIVE-RESTORATIVE ${ }^{\mathrm{TM}}$

7. Matos AB, Trevelin BTF, Francisconi-Dos-Rios LF, Siriani LK and Cardoso MV: Bonding efficiency and durability current possibilities. Brazilian Oral Research 2017;31:e57. 
8. Da Rosa WLO, Piva E and Da Silva AF: Bond strength of universal adhesives: A systemic review and meta-analysis. Journal of Dentistry 2015;43:765-776.

9. Sauro S, Makeeva I, Faus-Matoses V, Foschi F, Giovarruscio M, Pires PM et al: Effects of ions-releasing restorative materials on the dentine bonding longevity of modern universal adhesives after load-cycle and prolonged artificial saliva aging. Materials 2019;12(5):722.

10. Isolan CP, Valente LL, Munchow EA, Basso GR, Pimentel $\mathrm{AH}$, Schwantz JK et al: Bond strength of a universal bonding agent and other contemporary dental adhesives applied on enamel, dentin, composite, and porcelain. Applied Adhesion Science 2014;2:25.

11. Rodrigues JA, Oliveira GPF and Amaral CM: Effect of thickener agents on dental enamel microhardness submitted to at-home bleaching. Brazilian Oral Research 2007;21(2):170-175.

12. El-Banna AH, El-korashy DI and Alian GA: Bonding effectiveness and microleakage of self-adhesive flowable composites. Egyptian Dental Journal 2015;61:1599-1614.

13. Cuevas-Suarez CE, da Rosa WLO, Lund RG, da Silva AF and Piva E: Bonding performance of universal adhesives: an updated systematic review and meta-analysis. Journal of Adhesive Dentistry 2019;21(1):7-26.

14. Pouyanfar H, Tabaii ES, Aghazadeh S, Nobari SPTN and Imani MM: Microtensile bond strength of composite to enamel using universal adhesive with/without acid etching compared to etch and rinse and self-etch bonding agents. Open Access Macedonian Journal of Medical Sciences 2018;6(11):2186-2192.

15. Khan A and Syed MR: A review of bioceramics-based dental restorative materials. Dental Materials Journal 2019;38(2):163-176.

16. Reis A, Zander-Grande C, Kossatz S, Stanislawczuk R, Manso A, Carvalho RM and Loguercio AD: Effect of mode of application on the microtensile bond strength of a selfetch and etch-and-rinse adhesive system. Operative Dentistry 2010;35(4):428-435.

17. Pashley DH, Tay FR, Breschi L, Tjäderhane L, Carvalho RM, Carrilho M and Tezvergil-Mutluay A: State of the art etchand-rinse adhesives. Dental Materials 2011;27(1):1-16.

18. Sakr OM: Microshear bond strength of bioactive restorative materials to dentin. International Journal of Dental Sciences and Research 2018;6(4):90-94.
19. Yoshida Y, Nagakane K, Fukuda R, Nakayama Y, Okazaki M, Shintani H et al: Comparative study on adhesive performance of functional monomers. Journal of Dental Research 2004;83(6):454-458.

20. Van Meerbeek B, Yoshihara K, Yoshida Y, Mine A, De Munck J and Van Landuyt KL: State of the art of self-etch adhesives. Dental Materials 2011;27(1):17-28.

21. Yoshihara K, Yoshida Y, Nagaoka N, Fukegawa D, Hayakawa S, Mine A et al: Nano-controlled molecular interaction at adhesive interfaces for hard tissue reconstruction. Acta Biomaterialia 2010;6(9):3573-3582.

22. Hanabusa M, Mine A, Kuboki T, Momoi Y, Van Ende A, Van Meerbeek B and De Munck J: Bonding effectiveness of a new "multi-mode" adhesive to enamel and dentine. Journal of Dentistry 2012;40:475-484.

23. De Cardoso GC, Nakanishi L, Isolan CP, Jardim PS and de Moraes RR: Bond stability of universal adhesives applied to dentin using etch- and-rinse or self-etch strategies. Brazilian Dental Journal 2019;30(5):467-475.

24. Armstrong S, Breschi L, Ozcan M, Pfefferkorn F, Ferrari $M$ and Van Meerbeek B: Academy of dental materials guidance on in vitro testing of dental composite bonding effectiveness to dentin/enamel using micro-tensile bond strength ( $\mu$ TBS) approach. Dental Materials 2017;33:133-143.

25. Tja"derhane L: Dentin bonding: can we make it last? Operative Dentistry 2015; 40(1):4-18.

26. Van Landuyt KL, Yoshida Y, Hirata I, Snauwaert J, De Munck J, Okazaki M et al: Influence of the chemical structure of functional monomers on their adhesive performance. Journal of Dental Research 2008;87(8):757-761.

27. Garoushi S, Vallittu PK and Lassila L: Characterization of fluoride releasing restorative dental materials. Dental Materials Journal 2018;37(2):293-300.

28. Tezvergil-Mutluay A, Seseogullari-Dirihan R, Feitosa VP, Cama G, Brauer DS and Sauro S: Effects of composites containing bioactive glasses on demineralized dentin. Journal of Dental Research 2017;96:999-1005.

29. Makowski GS and Ramsby ML: Differential effect of calcium phosphate and calcium pyrophosphate on binding of matrix metalloproteinases to fibrin: Comparison to a fibrinbinding protease from inflammatory joint fluids. Clinical and Experimental Immunology 2004;136:176-187. 